Article

\title{
A Method for Urban Flood Risk Assessment and Zoning Considering Road Environments and Terrain
}

\author{
Nengcheng Chen ${ }^{1,2} \mathbb{D}$, Shuang Yao ${ }^{1}$, Chao Wang ${ }^{1, *}{ }^{\mathbb{D}}$ and Wenying Du ${ }^{1} \mathbb{D}$ \\ 1 State Key Laboratory of Information Engineering in Surveying, Mapping and Remote Sensing, \\ Wuhan University, Wuhan 430079, China; cnc@whu.edu.cn (N.C.); yaoshuang@whu.edu.cn (S.Y.); \\ duwenying@whu.edu.cn (W.D.) \\ 2 Collaborative Innovation Center of Geospatial Technology, 129 Luoyu Road, Wuhan 430079, China \\ * Correspondence: c.wang@whu.edu.cn
}

Received: 4 April 2019; Accepted: 6 May 2019; Published: 14 May 2019

\begin{abstract}
Floods have been severely threatening social development worldwide. The occurrence of floods has multiple factors, and the flood risk considering road environments needs comprehensive analysis from meteorology, underlying surface, and urban road network. Thus, this study proposes an integrated method and constructs a road risk zoning model (RRZM). In the RRZM, submerged depth was obtained by the Soil Conservation Service (SCS) model, and the degree of road importance was obtained by the analytical hierarchy process (AHP) method. These two parts were used to characterize road vulnerability. Then the flood risk grade was evaluated based on the optimized artificial neural network (ANN). Finally, the results of flood risk assessment were obtained by road vulnerability and flood risk grade. The RRZM was applied to the Chang-Zhu-Tan Urban Agglomeration (CZTUA), China. The results showed that the spatial distributions of flood risk and the extent of road damage varied remarkably in different cities. Changsha was the most sensitive city to floods in the CZTUA. The flood risk zones were classified into six levels, and the vulnerable road sections identified from the risk zones at level 6 in the maps carried more traffic volume than others. By comparing with existing methods, it was found that the RRZM effectively reflected the spatial characteristics of flood risk considering road environments. It provides a new perspective for urban flood risk assessment and disaster response decision-making.
\end{abstract}

Keywords: urban flood; road environments; flood risk assessment; road risk zoning model; Chang-Zhu-Tan urban agglomeration

\section{Introduction}

As a serious natural disaster, floods happen frequently around the globe [1]. In recent decades, floods have been exacerbated by climate change and expanded urbanization [2]. People's lives and social development have been seriously threatened by floods [3]. In China, floods have caused many severe disasters that resulted in casualties and economic losses, particularly in urban areas $[4,5]$. With the acceleration of urbanization in China, the growing population, dense built-up areas and complex road networks are more exposed to floods. Meanwhile, impervious surfaces, which are largely adopted in urban areas, have made cities suffer severely in flood disasters [6]. As a kind of impervious surface, roads are not only important infrastructures of cities, but also key elements contributing to the urban economy [7]. However, roads are extremely vulnerable to floods, and damaged road sections have a huge impact on cities [2,8].

Many studies usually start with the rainfall-runoff models for the evolution process of floods, and the Soil Conservation Service (SCS) model, as one of the simplest and most effective methods, has been widely used. Papaioannou, et al. [9] proposed a methodology based on hydrological and flood 
inundation model and mapping techniques with the SCS method and the unit hydrograph theory for ungauged urban areas. Bouvier et al. [10] compared the efficiency of SCS and the Green-Ampt models coupled with the distributed Lag and Route for flood modelling. It can be seen that the SCS model is usually used for flood development mechanism, but it still need to be combined with Geographic Information System (GIS) and other methods for flood hazard and control.

As an effective means of controlling floods, flood risk assessment has been studied extensively [11]. There are several approaches for flood risk assessment, such as index model and scenario analysis. Wu et al. [12] built a risk assessment index system based on the hazards of the natural environment and the vulnerability of the economy by adopting GIS and analytic hierarchy process (AHP) methods. Glas et al. [13] developed a flood damage assessment model, then generated damage maps with 12 scenarios to test the sensitivity of the model. There are many analyses in different scenarios of urban flood risk assessment, but few in risk zoning of road environments considering factors systematically $[14,15]$. As a study scenario, "road environments" refers to the consideration of road impact on surrounding areas according to its attributes. The flood risk assessment and zoning considering road environments will take the effects of roads on the region as an important part of the overall work.

Thus, this study proposed a meteorology-land integrated method for urban flood risk assessment and zoning considering road environments. The method considered the flood situation and road conditions comprehensively. The main contributions of this study are to (1) construct the road risk zoning model (RRZM) for flood assessment; (2) obtain urban flood risk zoning maps, and analyze the spatial characteristics of flood risk with different scales and different flood risk grades; and (3) identify the vulnerable road sections based on the spatial differences among cities.

\section{Materials and Methods}

\subsection{Study Area}

The Chang-Zhu-Tan Urban Agglomeration (CZTUA) is located in the east-central part of China and is the core area of economy and urbanization in Hunan province (Figure 1). The total land area is about $28,000 \mathrm{~km}^{2}$, accounting for $13.3 \%$ of the province. The urban agglomeration consists of three cities, Changsha, Zhuzhou, and Xiangtan. These three cities rank first, third, and second, respectively, in per capita Gross Domestic Product (GDP) in Hunan province. There are many railway lines, domestic expressways, and national highways connecting the three cities. The CZTUA is regarded as national transportation hub with its convenient and developed traffic network.

The cities are connected by the Xiangjiang, Zishui, Yuanjiang, and Lishui Rivers in the CZTUA. There are 36 rivers with a total length of $603 \mathrm{~km}$. The CZTUA is located in an area with subtropical monsoon humid climate, with average annual rainfall of $1414.4 \mathrm{~mm}$, and floods occur frequently because of the abundant rainfall. The catastrophic floods in 1994, 1998, and 2017 caused great damage in the CZTUA. Road network is vulnerable by floods, affecting the urban agglomeration development.

\subsection{Methods}

The road risk zoning model (RRZM) proposed for flood risk assessment and zoning considering road environments includes three main steps. First, the submerged depth is obtained by land use type and rainfall, and basic road data are used to evaluate the grade of road importance. These two parts are used to represent the road vulnerability. Second, based on the flood hazard factors and the exposure factors of hazard-affected bodies, the grade of urban flood risk is assessed by a neural network algorithm. Third, the road vulnerability and flood risk grade obtained in the previous two steps are combined to analyze urban floods. Finally, flood risk assessment and zoning maps are obtained. The framework is illustrated in Figure 2. 


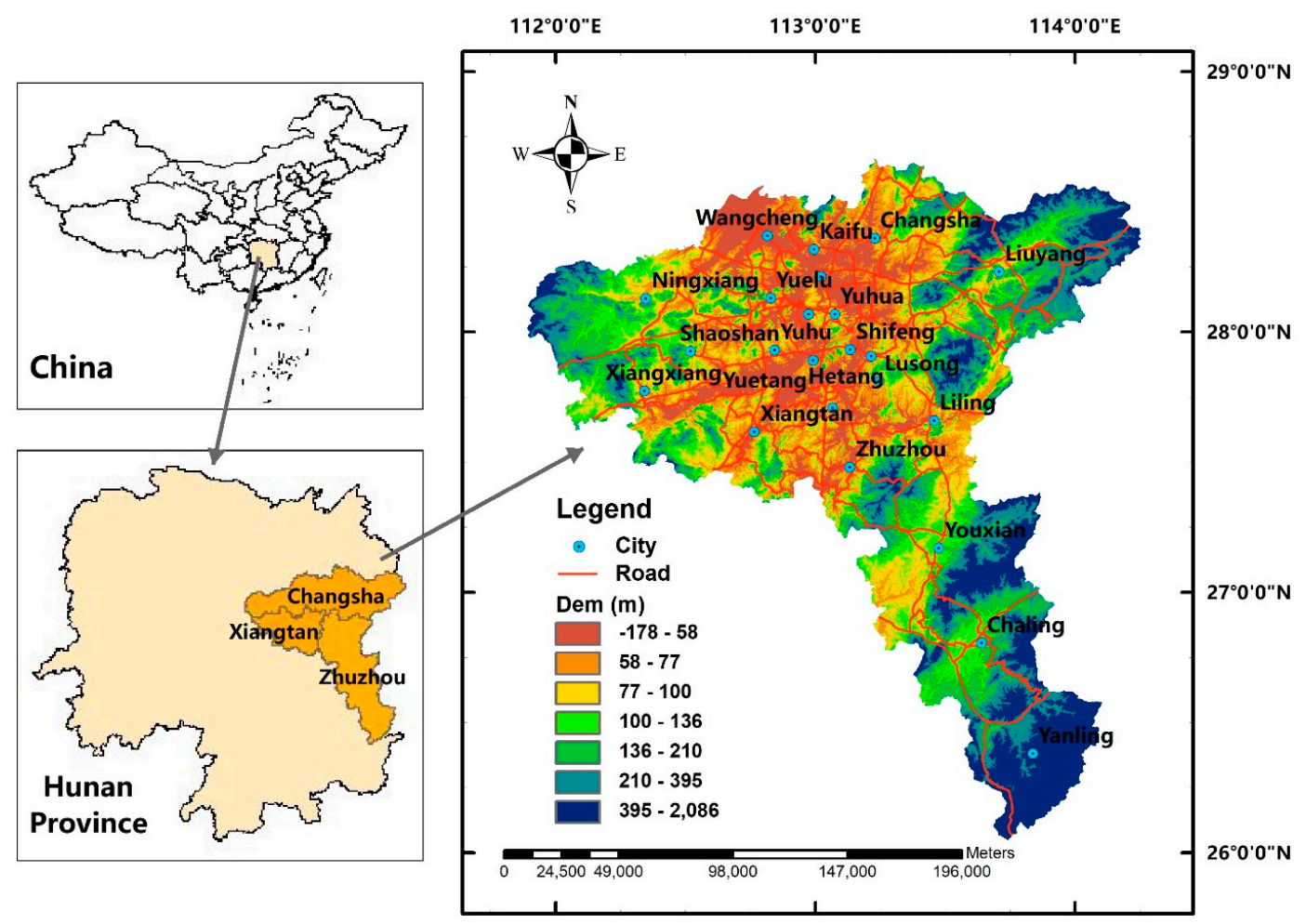

Figure 1. Location maps of Chang-Zhu-Tan Urban Agglomeration (CZTUA).

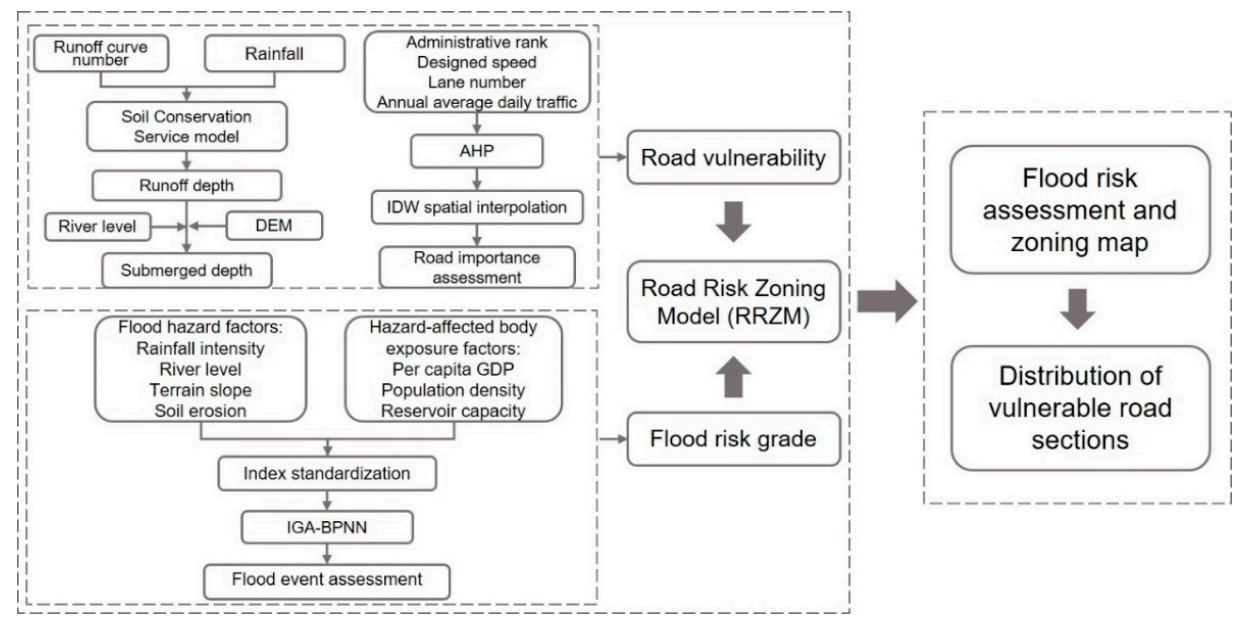

Figure 2. Framework for flood risk assessment and zoning.

\subsubsection{Vulnerability of Road Environments}

Submerged Depth

When the river level rises due to heavy rain, floods are likely to occur, which result in submergence of the urban surface. The submerged depth in this study is a function of runoff depth, river level, and terrain elevation [16]. The runoff depth is calculated by the Soil Conservation Service (SCS) model, which was proposed by the United States Department of Agriculture [17]. As an important parameter in the SCS model, the runoff curve number $(\mathrm{CN})$ represents the runoff potential of different underlying surface. The terrain elevation required by the calculation is obtained by a digital elevation model (DEM). 
The SCS model is widely used for surface runoff calculation [18], and the main formulas are as follows:

$$
\begin{gathered}
Q=\frac{\left(P-I_{a}\right)^{2}}{P-I_{a}+S} \\
S=\frac{25400}{C N}-254
\end{gathered}
$$

where $Q$ is the runoff depth (mm), $P$ is the total rainfall $(\mathrm{mm}), I_{a}$ is the initial abstracted rainfall $(\mathrm{mm})$, and $S$ is the potential maximum rainfall infiltration $(\mathrm{mm})$, and in general $I_{a}=0.2 S$ [17]. In the case of relatively stable soil condition, the change of $C N$ is mainly caused by the change of land use [19]. The code for design of building water supply and drainage of China (GB50015-2003) and the code for design of outdoor wastewater engineering of China (GB50014-2006) describe the runoff coefficient of different underlying surface types and regional conditions [20]. Referring to the method of Wang, et al. [21] and $\mathrm{Su}$, et al. [19], CN was calculated from runoff coefficients of different land use types, and the specific values are shown in Table 1.

Table 1. Runoff coefficient and runoff curve number $(\mathrm{CN})$ of different land use types.

\begin{tabular}{cccccccc}
\hline Land Use Types & Forest & Herbaceous & Cropland & Wetland & Bare Area & Urban & Water \\
\hline Runoff coefficient & 0.15 & 0.2 & 0.6 & 0.5 & 0.7 & 0.9 & 1 \\
CN & 26 & 30 & 56 & 48 & 68 & 90 & 95 \\
\hline
\end{tabular}

Since $C N$ in this study was mainly determined by land use type, the uncertainty came from the accuracy of land use type. The spatial resolution of land use type is $30 \mathrm{~m}$, which cannot meet the requirements of community-scale. The accuracy of urban runoff depth will be further improved by improving the classification accuracy of land use.

The rising river level caused by heavy precipitation leads to the occurrence of flood, so the flood depth is calculated by adding the original river level and the surface runoff depth. The formulas of submerged depth are as follows:

$$
\begin{aligned}
& D_{F}=Q+H_{R} \\
& D_{S}=D_{F}-H
\end{aligned}
$$

where $D_{F}$ is the flood depth (mm), $H_{R}$ is the river level (mm), $D_{S}$ is the submerged depth (mm), and $H$ is the terrain elevation ( $\mathrm{mm}$ ). The data of land use type were from GLOBLAND30, provided by the National Geomatics Center of China (http://www.globallandcover.com). The DEM was provided by the Geospatial Data Cloud site, Computer Network Information Center, Chinese Academy of Sciences (http://www.gscloud.cn).

\section{Road Importance Assessment}

Good traffic conditions are key to promoting economic growth [7], thus traffic delays and road network damage caused by urban flooding have a serious impact on society [2]. The traffic capacity and service levels of roads vary in cities, and roads also suffer different kinds of damage by floods. Therefore, it is important to identify the risk points of road networks in flood risk assessment [7,22].

The road importance is mainly determined by the road network structure and capacity [23]. There are four indices from the Department of Transportation of Hunan Province to evaluate road importance: road administration grade, design speed, number of lanes, and annual average daily traffic. Among these indices, the annual average daily traffic was obtained by actual monitoring, which has the greatest impact on traffic capacity. The other three indices were in accordance with the road construction regulations. The AHP [24] and expert scoring method were used for assigning weights of decision indices [25]. The weights calculated are in line with the actual situation and recognized by experts from the Department of Transportation of Hunan Province (Table 2). 
Table 2. Four basic road indices and their respective weights for road important assessment.

\begin{tabular}{ccccc}
\hline Index & $\begin{array}{c}\text { Road Administration } \\
\text { Grade }\end{array}$ & Design Speed & Number of Lanes & $\begin{array}{c}\text { Annual Average } \\
\text { Daily Traffic }\end{array}$ \\
\hline Weight & 0.051 & 0.256 & 0.117 & 0.576 \\
\hline
\end{tabular}

Then the assessment results calculated by the four indices were assigned to the nodes of the road networks. Based on these nodes, the inverse distance weighting (IDW) method [26] was used to obtain the raster dataset of urban road importance assessment in the study area. The value of each cell represents the service level and degree of influence of adjacent roads on this point. The larger the cell value, the more vulnerable the point is and the greater the damage by floods to this point.

\subsubsection{Flood Risk Grade}

A flood is a combination of factors, and the relationship between these factors is complex and non-linear. Artificial neural network (ANN) algorithms have obvious advantages in dealing with non-linear mapping relationships and are often used as simulation models in hydrological systems [27,28]. There have been many studies on flood forecasting and risk assessment [29-31]. Among these algorithms, the back propagation neural network (BPNN) [32] is widely used as a neural network with an effective weight adjustment [33,34].

The BPNN is a forward neural network, including input layers, hidden layers, and output layers. The forward propagation of the BPNN is a learning process that connects input signals and weights, and the back propagation is a process of error adjustment to approach the true value. The output signal is obtained using the follow formula [31]:

$$
Y_{k}=f\left(\sum_{i} W_{i j} X_{i}-\theta_{j}\right)
$$

where $Y_{k}$ is the output signal of node $k, f(\cdot)$ denotes the activation function, $W_{i j}$ is the weight between node $i$ and node $j, X_{i}$ is the input signal of node $i$, and $\theta_{j}$ is the bias of node $j$.

However, the BPNN has the disadvantage of slow convergence, and some algorithms are generally used for optimization of the BPNN. In this study, the immune genetic algorithm (IGA) [35], which has a better optimization effect than the Genetic Algorithm (GA) [36], is adopted to optimize the parameters of the BPNN [37]. The inputs are flood hazard factors, including rainfall intensity, river level, terrain slope, and soil erosion, and exposure factors of hazard-affected bodies, including per capita GDP, population density, and reservoir capacity. The data of factors for BPNN training were derived from historical flood events. Rainfall intensity referred to the maximum two days' precipitation, and river level referred to the maximum water level in each flood event. After inputting these standardized indices, this BPNN was trained to obtain flood risk grades.

The hydrological data were provided by the National Meteorological Information Center (http: //data.cma.cn/), the data of underlying surface were provided by the Resource and Environment Data Cloud Platform (http://www.resdc.cn/Default.aspx), and the socio-economic data came from statistical yearbooks.

\subsubsection{Flood Risk Assessment and Zoning}

Hazard is the natural attribute of disaster with a function of disaster scale, and vulnerability is the social attribute of disaster with a function of social economy and ecological environment. Exposure is used to describe the quantitative characteristics of disaster-affected bodies in social attributes [38,39]. The combination of hazard, exposure, and vulnerability leads to disaster risk [40], which is a common definition of risk. Therefore, this study of urban flood risk considering road environments is analyzed from the perspective of hazard, exposure, and vulnerability. The RRZM was proposed for flood risk 
assessment and zoning, whose inputs were the vulnerability of the road environments and flood risk grade obtained above.

The model formulas are as follows:

$$
\begin{aligned}
& V=\left(\alpha D_{S}+\beta R\right) \times G_{i} \\
& G_{i}=\left\{G_{1}, G_{2}, G_{3}, G_{4}\right\}
\end{aligned}
$$

where $V$ denotes the value of flood risk at each point; $D_{S}$ is the submerged depth; $R$ is the value of road importance ( $D_{S}$ and $R$ need to be standardized before inputting); $\alpha$ and $\beta$ are the tuning parameters of this model, and their default ratio is $1: 1 ; G_{i}$ is the flood risk grade indicating the extent of damage of each flood event which was obtained by Section 2.2.2. The four types of $G_{i}$ are general, greater, significant, and catastrophic flood risk, according to the flood disaster assessment of China (SL 579-2012), and the values are 1,2,3, and 4 respectively.

The value $V$ at each point of urban flood risk considering road environments was classified into six levels, from 1 to 6 , using the natural breaks technique for risk analysis [41]. Based on the summation of squares of deviation, this method tries to minimize the difference within each classification and maximize the difference between classifications [7,42]. According to the flood events with historical records, the natural breaks technique was used in ArcGIS and then fine-tuned to make the risk zoning levels match the actual disaster. The higher the risk zoning level, the more vulnerable the area is to floods.

The ratio between the two tuning parameters depends on the importance of terrain and roads in different areas. In some regions with high terrain, urban floods do not tend to occur when it rains. The roads play an important role because of their high density and accessibility in some regions, and roads there are greatly affected by floods. The zoning results can be adjusted by the ratios for different situations. These characteristics of the RRZM can reflect the spatial heterogeneity of flood risk.

Different flood risk grades not only indicate the degrees of damage caused by floods, but also represent different situations and scenarios for flood zoning. In conclusion, the RRZM is helpful for the spatial analysis of urban flood distribution and the scenario analysis of different flood risk degrees.

\section{Results}

\subsection{Urban Agglomeration Scale: A Case Study of the CZTUA}

\subsubsection{Results of Flood Risk Zoning}

The catastrophic flood event in Hunan province in June 1997 was taken as an example, with the maximum rainfall of two days reaching $249.6 \mathrm{~mm}$. The RRZM was applied to the CZTUA (ratio of $\alpha$ to $\beta$ is 1). The maps of submerged depth, road importance assessment, and flood risk zoning were obtained successively (Figure 3).

A total of 40 historical flood events in the CZTUA were selected as reference samples to verify the results of flood risk zoning (10 samples for each flood risk grade). The flood risk grades and regional division of these historical flood events were evaluated by the handbook for heavy rain flood estimation in Hunan province and flood disaster assessment (SL 579-2012), which defines floods according to the statistical data of disaster losses. For example, when the death toll reached 100 or the direct economic losses reached 20 billion yuan, the flood risk was directly identified as a catastrophic flood in flood disaster assessment (SL 579-2012). The results of the RRZM were compared with actual assessments of the flood events (Table 3). 


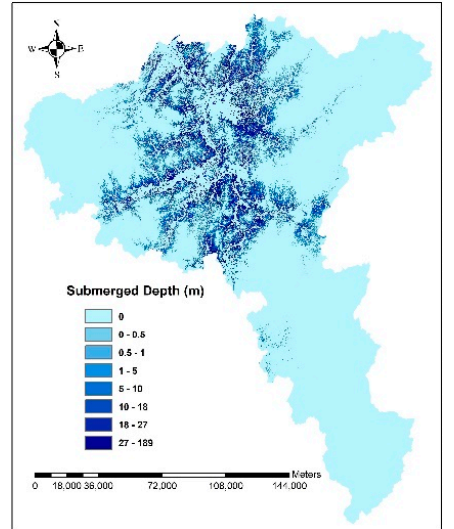

(a)

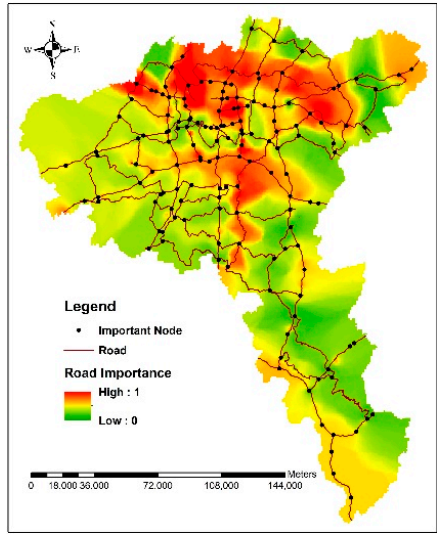

(b)

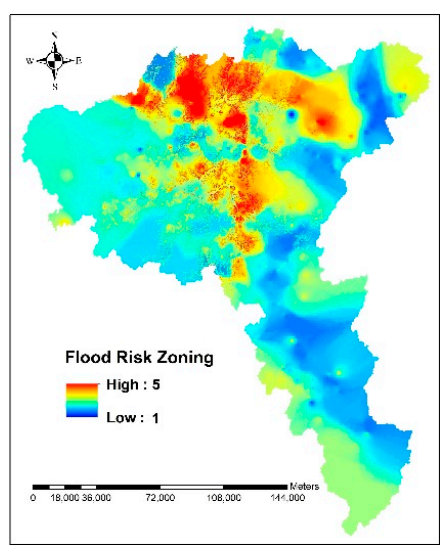

(c)

Figure 3. Three major resulting maps obtained by the road risk zoning model (RRZM) in the Chang-Zhu-Tan Urban Agglomeration (CZTUA): (a) map of submerged depth; (b) map of road importance assessment; (c) map of flood risk zoning considering road environments.

Table 3. Comparison of the samples and the results of road risk zoning model (RRZM).

\begin{tabular}{cccccc}
\hline & Sample Size & Correct Evaluation & Underestimate & Overvalued & Accuracy \\
\hline Testing & 40 & 35 & 1 & 4 & $87.5 \%$ \\
\hline
\end{tabular}

According to the comparison, it was found that five samples were wrongly estimated, of which one was level 4 but the result of the RRZM was evaluated as level 3. The risk zoning levels of the other four samples were overestimated. The remaining 35 samples were correctly evaluated. This shows that the RRZM is reliable and the results of risk zoning can provide a reference for flood prevention.

To evaluate the flood risk grades, the seven indices were selected based on the available information. The other four indices were used to evaluate the importance of roads. The selection and precision of the indices have a great influence on the accuracy of results. Further research on the selection of these indices is needed to improve the accuracy of flood risk zoning.

\subsubsection{Zoning at Different Flood Risk Grades}

Risk zoning considering road environments was discussed according to four flood risk grades, and the analyses at different grades were considered as different scenario analyses of the study area. The examples of the four flood risk grades were drawn from the historical flood events of the CZTUA: the rainfall of general risk was $36.3 \mathrm{~mm}$ in August 1997, that of greater risk was $98.2 \mathrm{~mm}$ in July 1992, that of significant risk was $150.8 \mathrm{~mm}$ in June 2000, and that of catastrophic risk was $249.6 \mathrm{~mm}$ in June 1997. The risk zoning maps considering road environments of urban agglomeration for different flood risk grades are shown in Figure 4.

As shown in Figure 4a, most areas are at levels 1 to 3 when a general flood occurs. The higher the flood risk grade, the larger the areas at levels 5 and 6. It can be seen that zones at level 6 in Figure 4c,d are mainly in the built-up areas of cities, which are more in the Xiangjiang River Basin plain, with high road density and urbanization. The zones at level 6 are the most vulnerable: if these zones are damaged by floods, it will have a great impact on the whole city. 


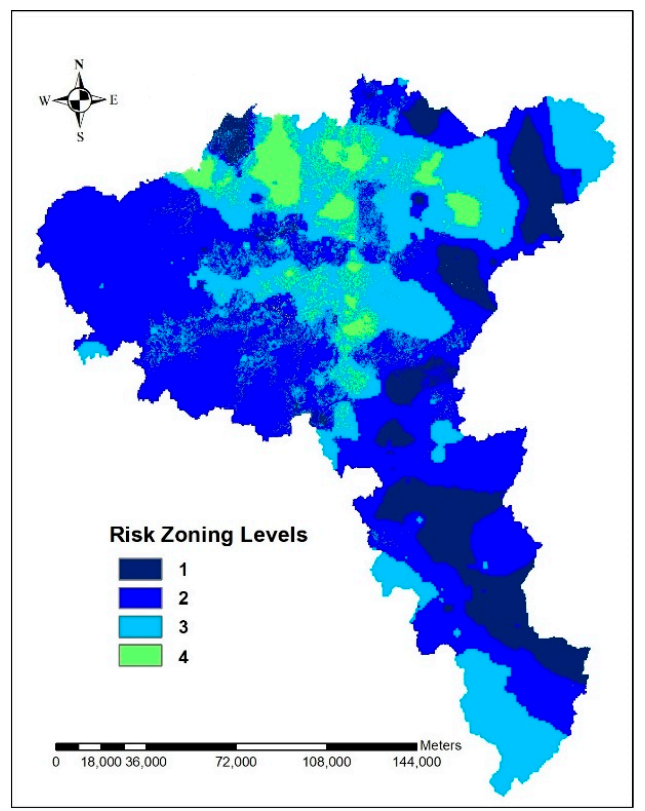

(a)

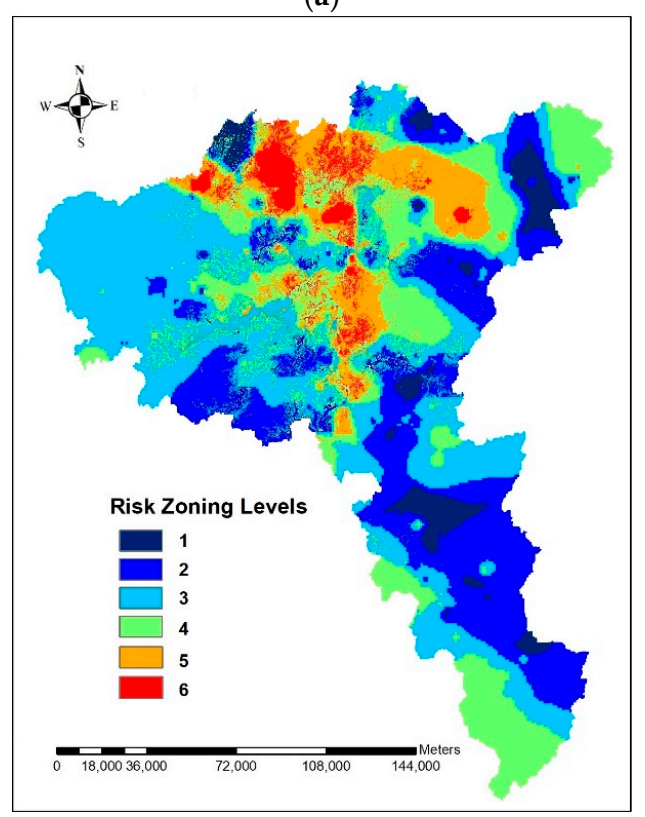

(c)

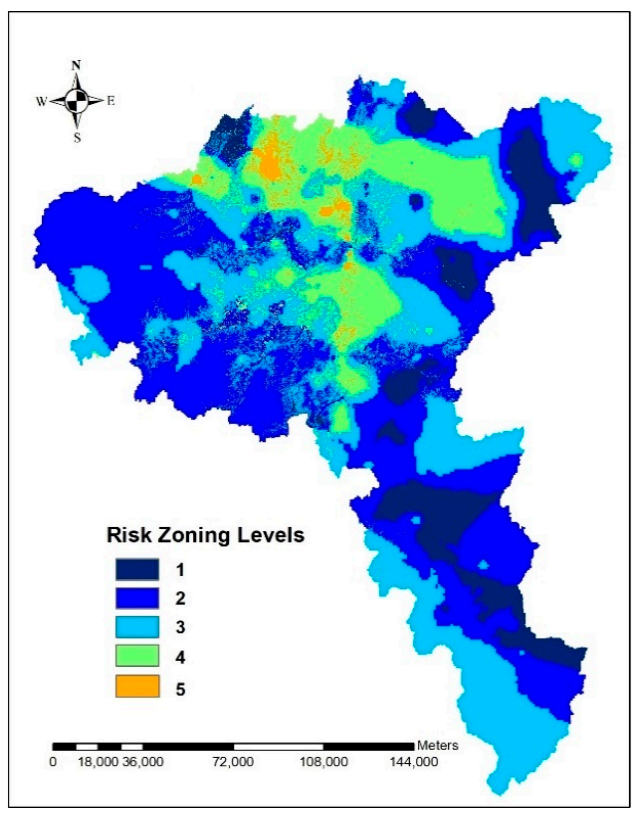

(b)

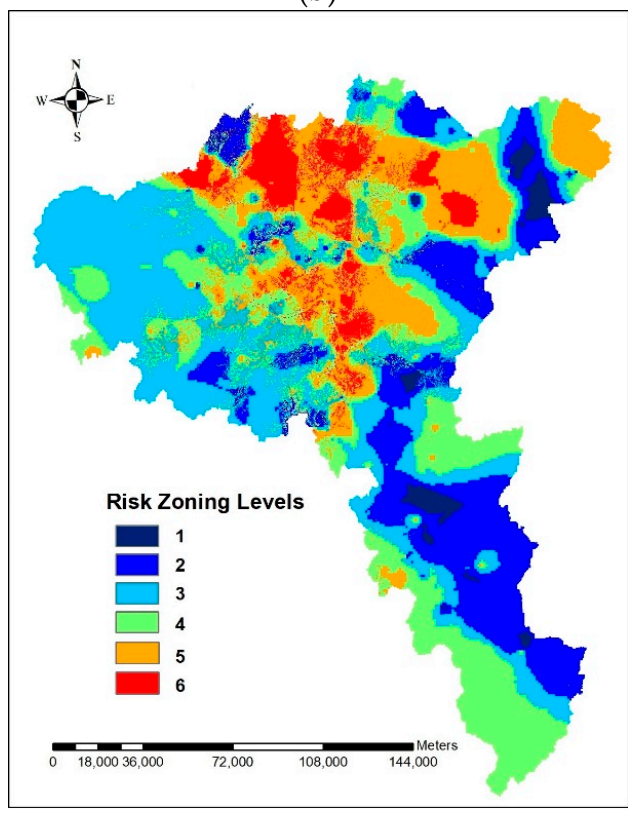

(d)

Figure 4. Risk zoning whose levels are up to 6 in road environments of the Chang-Zhu-Tan Urban Agglomeration (CZTUA) under four flood risk grades. (a) Risk zoning map under general flood. (b) Risk zoning map under greater flood. (c) Risk zoning map under significant flood. (d) Risk zoning map under catastrophic flood.

The zones at levels 4 to 6 are defined as sensitive road areas that are more damaged by floods than other zones. The percentages of areas at different flood risk zoning levels under the four flood risk grades are shown in Figure 5. The proportion of sensitive road areas in the total area increases with the improvement of flood risk grade, and the proportion is more than $50 \%$ in a catastrophic flood. By then the CZTUA would be in an emergency state and socio-economic activities would be severely affected by catastrophic floods. 


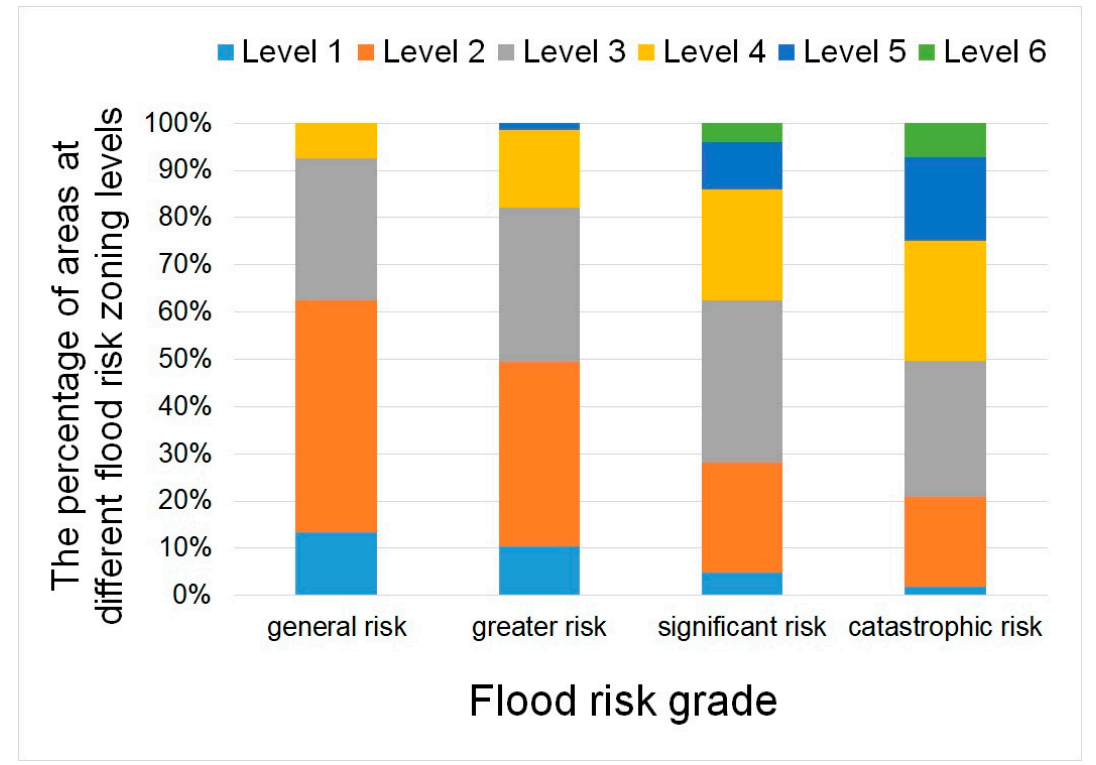

Figure 5. Percentages of areas at different flood risk zoning levels under four flood risk grades in the Chang-Zhu-Tan Urban Agglomeration (CZTUA).

\subsection{Single Urban Scale: A Case Study of Xiangtan City}

The RRZM was applied to a single urban scale with Xiangtan city as an example. The rainfall of the model input was $249.6 \mathrm{~mm}$ with a historical flood event in June 1997. The model evaluated the risk of this flood as grade 4, which is catastrophic flood risk. When the ratio of parameter $\alpha$ to parameter $\beta$ is 1:1 in the RRZM, the map of flood risk zoning considering road environments is as shown in Figure 6.

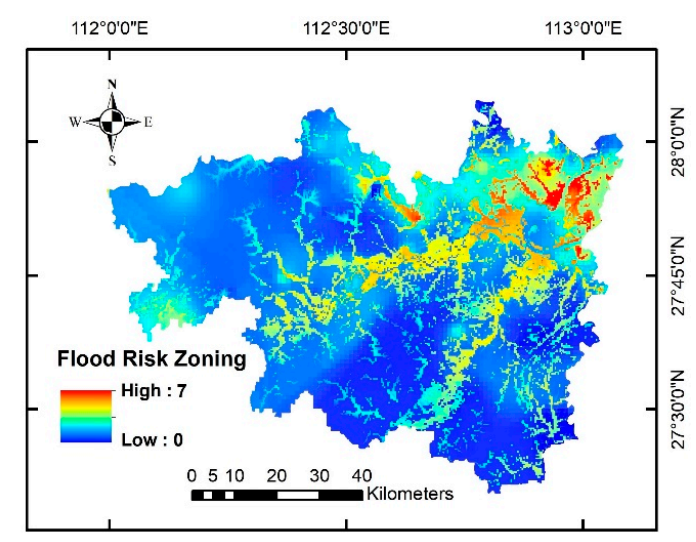

Figure 6. Map of flood risk zoning in Xiangtan road environments when the ratio of $\alpha$ to $\beta$ is $1: 1$ in the road risk zoning model (RRZM).

Variations in the weight of submerged depth and road importance have different effects on the flood risk zoning. As shown in Figure 6, the distribution of flood risk zoning is similar to that of road networks, which indicates that the results of road importance assessment contribute more than submerged depth to this zoning. However, compared with real flood events, it is found that some areas less damaged by floods are mistakenly divided into risk zones at level 4 or above. These areas are located in the southwest of Xiangtan city, where the terrain is higher and roads are less affected by floods. Therefore, it is necessary to increase the weight of submerged depth and reduce that of roads in the RRZM. When the ratio of $\alpha$ to $\beta$ is 3:2 (Figure 7), the risk zoning is more consistent with the actual situation of floods in Xiangtan. 


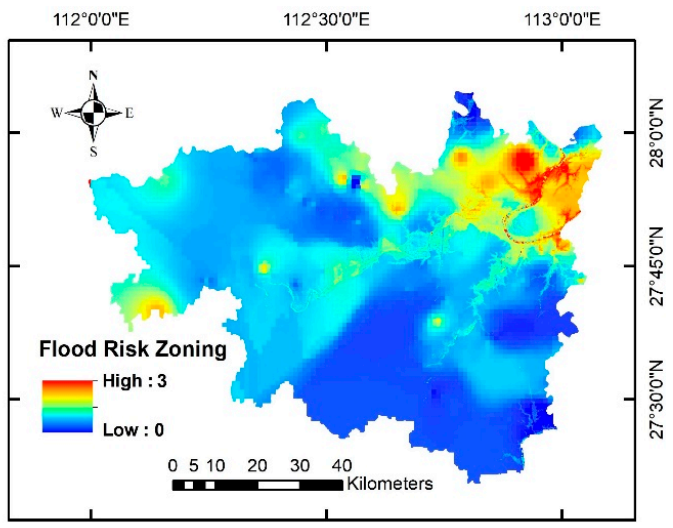

Figure 7. Map of flood risk zoning in Xiangtan road environments when the ratio of $\alpha$ to $\beta$ is $3: 2$ in the road risk zoning model (RRZM).

The four flood events were used to study single urban scale and were the same as in the urban agglomeration scale (Figure 8). Compared with remote sensing images, it is found that most of the zones at levels 5 and 6 are located on both sides of the Xiangjiang River, where the road networks are intensive. Most of these areas are impervious and prone to flooding. The zones at levels 1 and 2 are mostly in the areas with high terrain, sparse road network, and dense vegetation coverage. All of these indicate that flood risk is closely related to road network and geographic environments. As shown in the areas of different flood risk levels in Figure 8, the conclusions of the study have been proved.

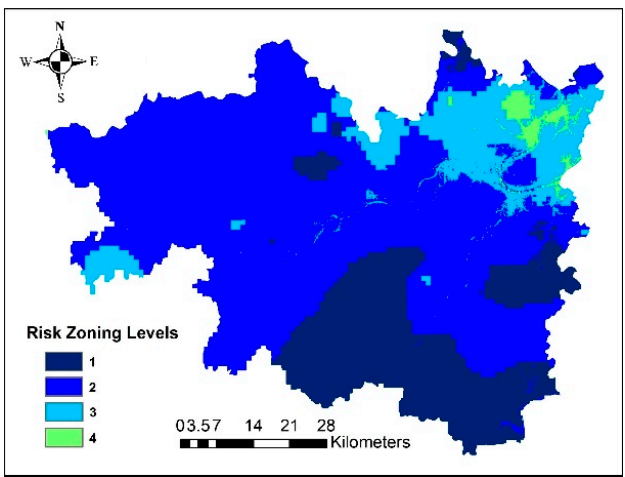

(a)

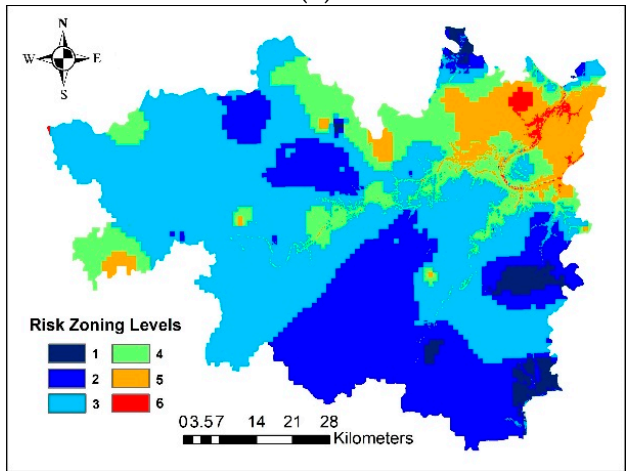

(c)

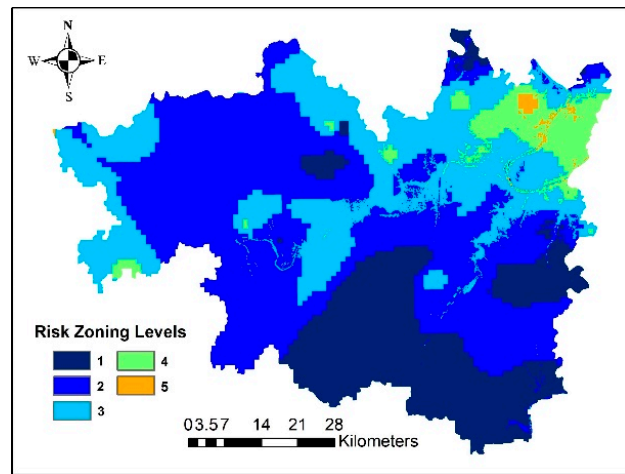

(b)

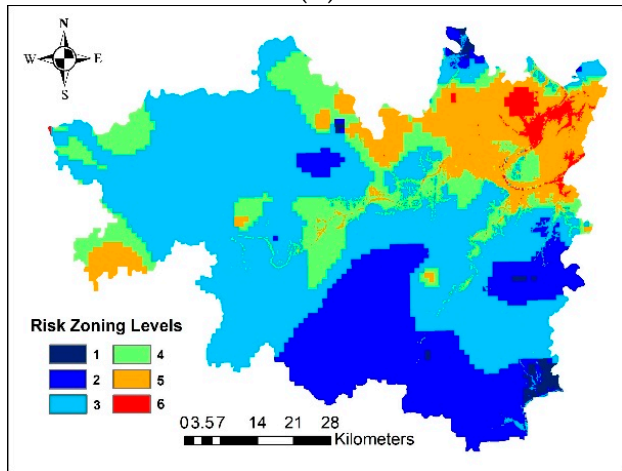

(d)

Figure 8. Risk zoning whose levels are up to 6 in road environments of Xiangtan under four flood risk grades. (a) Risk zoning map under general flood. (b) Risk zoning map under greater flood. (c) Risk zoning map under significant flood. (d) Risk zoning map under catastrophic flood. 
The percentages of areas at different flood risk zoning levels under the four flood risk grades are shown in Figure 9. The zoning results of Xiangtan city are different from those of the CZTUA under the four grades. In the event of catastrophic flood, the sensitive road areas account for less than $50 \%$ of the total area, and most areas are at level 3. Because of its higher terrain, Xiangtan city is less affected by floods than some cities in the CZTUA, which highlights the key role of topography in flood risk zoning. The difference between the results of flood risk zoning at the single urban scale and at the urban agglomeration scale reflects the influence of spatial heterogeneity on flood risk assessment and zoning.

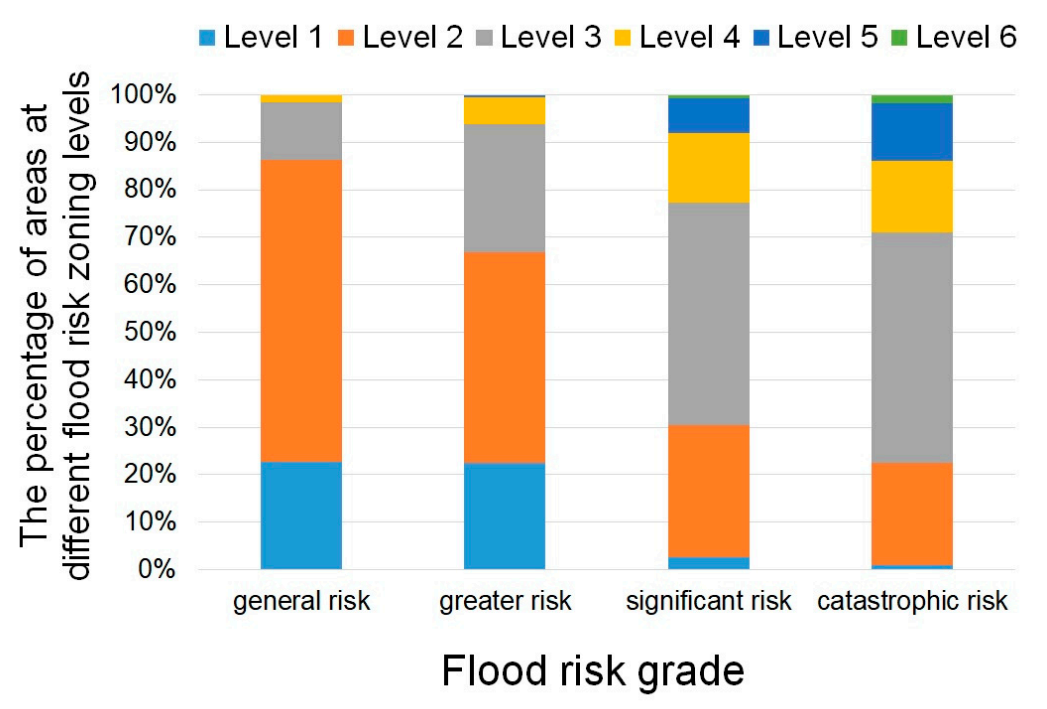

Figure 9. Percentages of areas at different flood risk zoning levels under four flood risk grades in Xiangtan.

Based on the situation of Xiangtan city, the parameters $\alpha$ and $\beta$ of Changsha city and Zhuzhou city were adjusted by comparing the data of DEM and urbanization indices among the three cities in Table 4. Changsha city has the highest urbanization level and lower terrain than Xiangtan city, so it is necessary to increase the proportion of road importance in the formula (6). The ratio of $\alpha$ to $\beta$ is 1:3 after manually adjusting. Similarly, the ratio of $\alpha$ to $\beta$ is 4:3 in Zhuzhou city. The flood risk zoning levels of Changsha and Zhuzhou city obtained after adjusting parameters have a higher consistency with actual disaster situation.

Table 4. Flood risk and urbanization indices of Changsha, Zhuzhou, Xiangtan.

\begin{tabular}{ccccc}
\hline \multirow{2}{*}{ City } & \multicolumn{2}{c}{ Flood Risk } & \multicolumn{3}{c}{ Urbanization Level } \\
\cline { 2 - 5 } & $\begin{array}{c}\text { Sensitive Road } \\
\text { Area }\end{array}$ & $\begin{array}{c}\text { Urban Area to } \\
\text { Total Area }\end{array}$ & Urban Population & $\begin{array}{c}\text { Urban Road } \\
\left.\text { Density (km/km } \mathbf{k n}^{\mathbf{2}}\right)\end{array}$ \\
\hline Changsha & $29.46 \%$ & $1.27 \%$ & $67.69 \%$ & 1.295 \\
Zhuzhou & $16.25 \%$ & $0.13 \%$ & $55.48 \%$ & 1.196 \\
Xiangtan & $10.71 \%$ & $0.31 \%$ & $50.11 \%$ & 1.290 \\
\hline
\end{tabular}




\section{Discussion}

\subsection{Discussion of Flood Risk Zoning Levels}

\subsubsection{Flood Risk Zoning Levels of the CZTUA}

Taking the rainfall of $249.6 \mathrm{~mm}$ of catastrophic flood risk as an example, the RRZM was applied to Changsha city, Zhuzhou city, and Xiangtan city, and parameters $\alpha$ and $\beta$ were adjusted according to Section 3.2. Figure 10 shows the percentages of areas at different risk zoning levels in the three cities.

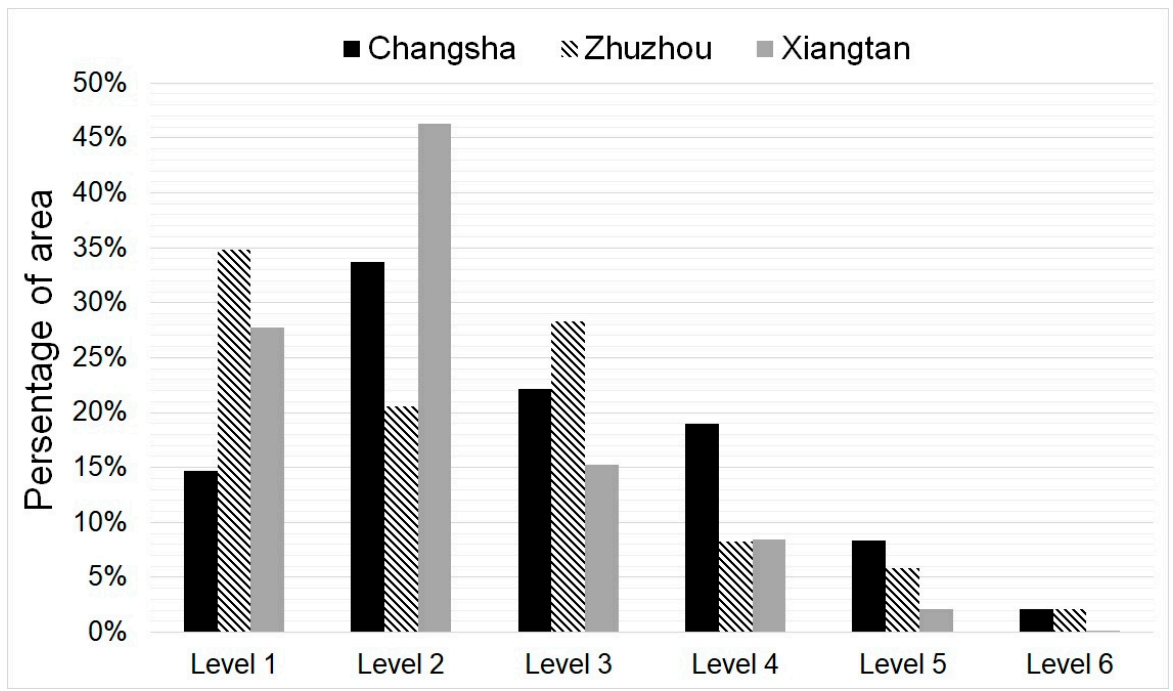

Figure 10. Percentages of areas at different risk zoning levels in Changsha, Zhuzhou, and Xiangtan in a catastrophic flood risk.

In case of catastrophic floods, the affected areas are mostly at level 1 or 2 of risk zoning in Changsha, Zhuzhou and Xiangtan. The risk zoning areas at levels 1 and 2 account for $48.42 \%$ of the total area in Changsha, 55.41\% in Zhuzhou, and 74.06\% in Xiangtan. This indicates that about half of the area in the three cities is less affected by floods. These regions are mostly mountainous areas with high altitude and dense vegetation. It can be found that the proportion of risk zoning areas at levels 4, 5 and 6 in Changsha is the largest among the three cities (Figure 10). As Changsha is highly urbanized (Table 4), the proportion of urban area to total area is larger than that in Zhuzhou and Xiangtan, and the urban road density is the biggest in the three cities. The sensitive road areas are mostly in built-up urban areas, where the road networks are dense. If sensitive road areas are damaged by floods, urban socio-economic activities will be seriously affected. Therefore, it is necessary to pay more attention to these sensitive road areas when urban flood risk is evaluated.

\subsubsection{Flood Risk of Roads in Cities and Counties}

The CZTUA consists of Changsha, Zhuzhou, and Xiangtan, including 23 cities, counties, and districts. When floods occur, the degree of flood damage varies from place to place due to the environmental differences. According to the average of flood risk zoning levels within each region in a catastrophic flood, the impact on the 23 cities, counties, and districts is classified into six levels. The most vulnerable sections of the road networks in floods are given by comparing the sections in sensitive road areas within the region. The flood risk zoning levels, the percentage of section length in sensitive road areas to the total length, and the most vulnerable road sections of the 23 regions in the CZTUA are listed in Table 5. 
Table 5. Flood risk zoning levels, percentage of section length in sensitive road areas to total length, and the most vulnerable road sections of 23 cities, counties, districts in the Chang-Zhu-Tan Urban Agglomeration (CZTUA).

\begin{tabular}{|c|c|c|c|c|}
\hline City & County or District & Flood Risk Zoning Level & $\begin{array}{l}\text { Percentage of Sections in } \\
\text { Sensitive Road Areas }\end{array}$ & $\begin{array}{c}\text { Vulnerable Road Section } \\
\text { (Start and End of Route, Section } \\
\text { Code) }\end{array}$ \\
\hline \multirow{9}{*}{ Changsha } & Liuyang city & Level 3 & $34.95 \%$ & Liuyang-Dongyang, 003 \\
\hline & Ningxiang county & Level 3 & $30.46 \%$ & Liuyang-Ningxiang, 153 \\
\hline & Yuhua district & Level 4 & $42.36 \%$ & Changsha airport expressway, 001 \\
\hline & Tianxin district & Level 3 & $27.83 \%$ & Changsha expressway, 008 \\
\hline & Yuelu district & Level 3 & $21.67 \%$ & Changsha-Yiyang, 004 \\
\hline & Furong district & Level 5 & $62.33 \%$ & Beijing-Gangao, 010 \\
\hline & Kaifu district & Level 5 & $64.92 \%$ & Changsha-Qiaoyi, 002 \\
\hline & Changsha county & Level 6 & $79.27 \%$ & Liuyang-Ningxiang, 073 \\
\hline & Wangcheng district & Level 5 & $72.68 \%$ & Changsha-Yiyang, 009 \\
\hline \multirow{9}{*}{ Zhuzhou } & You county & Level 4 & $44.09 \%$ & Quanzhou-Nanning, 010 \\
\hline & Yanling county & Level 2 & $15.50 \%$ & Wuhan-Shenzhen, 031 \\
\hline & Liling city & Level 4 & $52.21 \%$ & Shanghai-Kunming, 001 \\
\hline & Hetang district & Level 5 & $64.23 \%$ & Shanghai-Kunming, 005 \\
\hline & Lusong district & Level 5 & $67.45 \%$ & Liuyang-Hengyang, 036 \\
\hline & Tianyuan district & Level 4 & $48.61 \%$ & Beijing-Gangao, 017 \\
\hline & Shifeng district & Level 5 & $60.30 \%$ & Changsha-Zhuzhou, 004 \\
\hline & Zhuzhou county & Level 5 & $68.72 \%$ & Liuyang-Hengyang, 040 \\
\hline & Chaling county & Level 3 & $22.95 \%$ & Wuhan-Shenzhen, 019 \\
\hline \multirow{5}{*}{ Xiangtan } & Xiangxiang city & Level 3 & $21.89 \%$ & Liling-Qizi, 124 \\
\hline & Shaoshan city & Level 4 & $31.89 \%$ & Shaoshan expressway, 003 \\
\hline & Yuetang district & Level 4 & $43.19 \%$ & Shanghai-Kunming, 011 \\
\hline & Xiangtan county & Level 3 & $25.12 \%$ & Zhuzhou-Shaoshan, 016 \\
\hline & Yuhu district & Level 4 & $40.57 \%$ & Changtan west highway, 002 \\
\hline
\end{tabular}


As can be seen in Table 4, Changsha county and Wangcheng district, where developed traffic areas are in the center of Changsha city, are most destroyed by catastrophic flood. Zhuzhou county and Lusong district, which are concentrated area of urbanization, suffer the most severe damage by floods in Zhuzhou city. Yuetang district is severely damaged by floods in Xiangtan city. These five areas are most seriously damaged by floods because they are located in the plain on either side of the Xiangjiang River with dense road networks.

The road section length in sensitive road areas accounts for a larger percentage of the total length, and more than $65 \%$ of the total road sections are in the sensitive road areas when the risk zoning level of the county or district is 5 or above. The vulnerable road sections (Figure 11), which carry more traffic volume than others, are the key parts of these regions. If the vulnerable sections are damaged by floods, the whole city will suffer great loss. The road sections of Changsha county and Zhuzhou county are the most seriously damaged by floods in the CZTUA. Sections of Liuyang-Ningxiang, Changsha-Yiyang and Liuyang-Hengyang roads are the most vulnerable sections of the whole network, and these need special attention and protection when a flood is coming. If the relevant data meet the community-scale, the indirect impact of damaged roads on connecting areas and the connectivity of the road network in flood events can be further studied on the basis of this study.

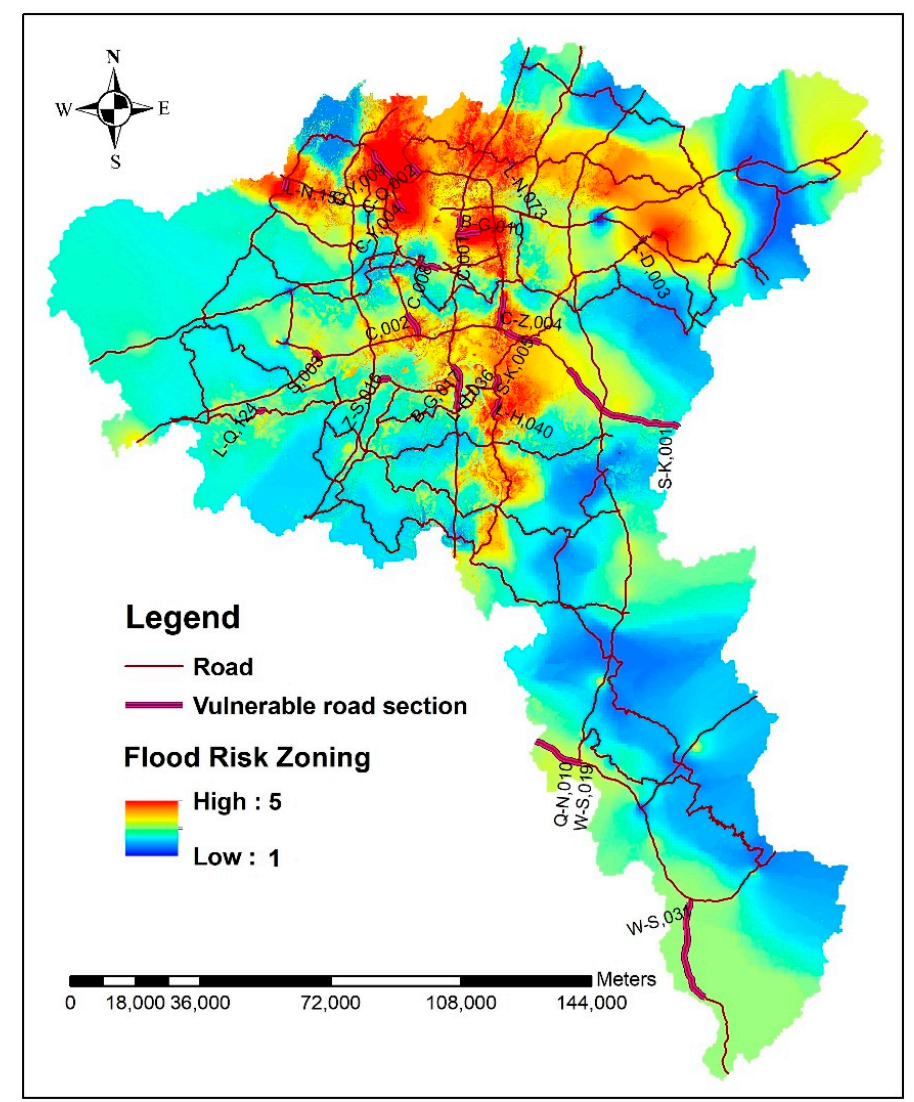

Figure 11. Distribution map of vulnerable road sections in 23 cities, counties, and districts in the Chang-Zhu-Tan Urban Agglomeration (CZTUA).

\subsection{Comparison of the Road Risk Zoning Model (RRZM) and Other Methods}

Studies about the impact of floods on roads are mostly based on factors that cause floods and flood-prone environments. Dawod, et al. [43] evaluated the impact of floods on roads through the characteristics of topography, geology, and land use types in the catchments. Yin, et al. [15] used the depth and duration of road inundation to assess the damage by floods on roads. However, the attributes of roads which are the disaster-bearing bodies, are equally important in flood risk assessment. This study evaluated the importance of roads based on the four basic elements of road data, and the 
zoning results took into account both flood inundation and road service level in cities. The resulting vulnerable road sections are more sensitive to flood: if they are damaged, it will have a serious impact on the whole road network.

Location and environment play important roles in any data-driven flood estimation approach. Jongman, et al. [44] qualitatively and quantitatively compared the assessments of seven flood damage models developed and applied by governments and academic institutions and pointed out that each of the seven models had its own application scope because of regional differentiation. Michielsen, et al. [22] used three modeling methods to predict the flood risk of two specified regions and proposed that the models were made for different areas to consider regional differences. Different regions have different environmental and traffic conditions, and the road connectivity in a single city is different from that in an urban agglomeration. The RRZM proposed in this study is suitable for different geographical environments by adjusting model parameters $\alpha$ and $\beta$, rather than building models separately according to regional differences.

However, the selection of the two parameters lacks a unified criterion. When the RRZM is applied to different regions, its parameters cannot be adapted and manual adjustment is required based on experience or data. This is a deficiency of the RRZM that needs to be improved in future work.

\section{Conclusions}

Considering flood damage and road vulnerability, the RRZM was proposed in this study for urban flood risk assessment and zoning considering road environments. Taking the CZTUA as a case study, the effectiveness of the RRZM was verified by comparing the results with actual flood situations. The study area was divided into up to six zones with different flood risk levels according to the service level and submergence degree of different roads. Changsha is the city most vulnerable to floods in the CZTUA, and there is the broadest distribution of sensitive roads in the plain of the Xiangjiang River Basin, where buildings are dense and traffic volume is huge. The road sections of Liuyang-Ningxiang, Changsha-Yiyang, and Liuyang-Hengyang in the CZTUA are the sections most vulnerable to floods, requiring continuous attention and corresponding protective measures. Evacuation routes considering different risk zoning levels should be arranged in advance before flood season. The flood risk zoning levels provide a basis for flood control and disaster relief arrangements.

The results of assessment and zoning in the RRZM can be used for scenario analysis under four flood risk grades (general, greater, significant, and catastrophic). The RRZM can also be adapted to different regional characteristics by adjusting its parameters, which reflects the flexibility of this model. However, the selection of parameters and evaluation indices in the RRZM lacks a unified standard. Future work will be devoted to the selection of these variables, which is conducive to improving the accuracy of results in the RRZM.

Author Contributions: Conceptualization, N.C.; methodology, C.W. and W.D.; software, S.Y.; validation, S.Y.; formal analysis, S.Y.; data curation, S.Y.; writing-original draft preparation, S.Y.; writing-review and editing, C.W. and W.D.; supervision, N.C.; project administration, N.C.

Funding: This research was funded by the National Key Research and Development Program of China (Grant no. 2017YFB0503803), the National Nature Science Foundation of China (NSFC) Program (Grant no. 41601406), the China Postdoctoral Science Foundation (Grant no. 2017M622502), and the CRSRI Open Research Program (Grant no. CKWV2018487/KY).

Acknowledgments: The authors are grateful to the National Geomatics Center of China for the data of land use type (http://www.globallandcover.com), the Geospatial Data Cloud site for the data of DEM (http://www.gscloud.cn), the National Meteorological Information Center for the hydrological data (http://data.cma.cn/), and the Resource and Environment Data Cloud Platform for the data of underlying surface (http://www.resdc.cn/Default.aspx). The authors are also grateful to anyone for their advice and help about this manuscript.

Conflicts of Interest: The authors declare no conflict of interest. 


\section{References}

1. Jha, A.K.; Bloch, R.; Lamond, J. Cities and Flooding: A Guide to Integrated Urban Flood Risk Management for the 21st Century; The World Bank: Washington, DC, USA, 2012.

2. Beiler, M.R.O.; Treat, C. Integrating GIS and AHP to Prioritize Transportation Infrastructure Using Sustainability Metrics. J. Infrastruct. Syst. 2015, 21, 04014053. [CrossRef]

3. Kundzewicz, Z.W.; Kanae, S.; Seneviratne, S.I.; Handmer, J.; Nicholls, N.; Peduzzi, P.; Mechler, R.; Bouwer, L.M.; Arnell, N.; Mach, K.; et al. Flood risk and climate change: Global and regional perspectives. Hydrol. Sci. J. 2014, 59, 1-28. [CrossRef]

4. Lu, X.X.; Ran, L.S. China flood havoc highlights poor urban planning. Nat. Hazards 2011, 56, 575-576. [CrossRef]

5. Zheng, Z.P.; Qi, S.Z.; Xu, Y.T. Questionable frequent occurrence of urban flood hazards in modern cities of China. Nat. Hazards 2013, 65, 1009-1010. [CrossRef]

6. Huong, H.T.L.; Pathirana, A. Urbanization and climate change impacts on future urban flooding in Can Tho city, Vietnam. Hydrol. Earth Syst. Sci. 2013, 17, 379-394. [CrossRef]

7. Karlsson, C.S.J.; Kalantari, Z.; Mortberg, U.; Olofsson, B.; Lyon, S.W. Natural Hazard Susceptibility Assessment for Road Planning Using Spatial Multi-Criteria Analysis. Environ. Manag. 2017, 60, 823-851. [CrossRef]

8. Kalantari, Z.; Folkeson, L. Road Drainage in Sweden: Current Practice and Suggestions for Adaptation to Climate Change. J. Infrastruct. Syst. 2013, 19, 147-156. [CrossRef]

9. Papaioannou, G.; Efstratiadis, A.; Vasiliades, L.; Loukas, A.; Papalexiou, S.M.; Koukouvinos, A.; Tsoukalas, I.; Kossieris, P. An Operational Method for Flood Directive Implementation in Ungauged Urban Areas. Hydrology 2018, 5, 24. [CrossRef]

10. Bouvier, C.; Bouchenaki, L.; Tramblay, Y. Comparison of SCS and Green-Ampt Distributed Models for Flood Modelling in a Small Cultivated Catchment in Senegal. Geosciences 2018, 8, 122. [CrossRef]

11. Salman, A.M.; Li, Y. Flood Risk Assessment, Future Trend Modeling, and Risk Communication: A Review of Ongoing Research. Nat. Hazards Rev. 2018, 19, 3.

12. Wu, Y.N.; Zhong, P.A.; Zhang, Y.; Xu, B.; Ma, B.; Yan, K. Integrated flood risk assessment and zonation method: A case study in Huaihe River basin, China. Nat. Hazards 2015, 78, 635-651. [CrossRef]

13. Glas, H.; Deruyter, G.; De Maeyer, P.; Mandal, A.; James-Williamson, S. Analyzing the sensitivity of a flood risk assessment model towards its input data. Nat. Hazard Earth Syst. 2016, 16, 2529-2542. [CrossRef]

14. Qi, H.L.; Tian, W.P.; Li, J.C. Regional Risk Evaluation of Flood Disasters for the Trunk-Highway in Shaanxi, China. Int. J. Env. Res. Public Health 2015, 12, 13861-13870. [CrossRef]

15. Yin, J.; Yu, D.P.; Yin, Z.; Liu, M.; He, Q. Evaluating the impact and risk of pluvial flash flood on intra-urban road network: A case study in the city center of Shanghai, China. J. Hydrol. 2016, 537, 138-145. [CrossRef]

16. Rahman, M.R.; Saha, S. Flood hazard zonation-A GIS aided multi criteria evaluation (MCE) approach with remotely sensed data. Int. J. Geoinf. 2007, 3, 25-35.

17. United States Department of Agriculture. Urban hydrology for small watersheds. Tech. Rel. 1986, 55, 2-6.

18. Yao, L.; Wei, W.; Yu, Y.; Xiao, J.; Chen, L.D. Rainfall-runoff risk characteristics of urban function zones in Beijing using the SCS-CN model. J. Geogr. Sci. 2018, 28, 656-668. [CrossRef]

19. Su, X.U.; Zhang, Y.; Dou, M.; Hua, R.; Zhou, Y. Spatial distribution of land use change in the Yangtze River Basin and the impact on runoff. Prog. Geogr. 2017, 36, 4.

20. Wang, Z.L.; Lai, C.G.; Chen, X.H.; Yang, B.; Zhao, S.W.; Bai, X.Y. Flood hazard risk assessment model based on random forest. J. Hydrol. 2015, 527, 1130-1141. [CrossRef]

21. Wang, H.; Wang, X.; Xi, W. SCS-CN-based approach for estimating collectable rainwater in waterrshed-scale. Trans. Chin. Soc. Agric. Eng. 2012, 28, 86-91.

22. Michielsen, A.; Kalantari, Z.; Lyon, S.W.; Liljegren, E. Predicting and communicating flood risk of transport infrastructure based on watershed characteristics. J. Environ. Manag. 2016, 182, 505-518. [CrossRef] [PubMed]

23. Cheng, S.P.; Cao, S.L.; Zhang, W. Analysis and application of urban road network structure system. Urban Roads Bridges Flood Control 2017, 5, 1-5. (In Chinese)

24. Saaty, T.L. A scaling method for priorities in hierarchical structures. J. Math. Psychol. 1977, 15, $234-281$. [CrossRef] 
25. Duan, L.Q.; Liu, L.G.; Guo, L.; Zhang, Y.J. Applying the AHP Method to the Weighted Values Determination of the Road Attributes. Hydrogr. Surv. Charting 2004, 3, 13.

26. Bartier, P.M.; Keller, C.P. Multivariate interpolation to incorporate thematic surface data using inverse distance weighting (IDW). Comput. Geosci. 1996, 22, 795-799. [CrossRef]

27. Chidthong, Y.; Tanaka, H.; Supharatid, S. Developing a hybrid multi-model for peak flood forecasting. Hydrol. Process. 2009, 23, 1725-1738. [CrossRef]

28. Sudheer, K.P.; Jain, A. Explaining the internal behaviour of artificial neural network river flow models. Hydrol. Process. 2004, 18, 833-844. [CrossRef]

29. Dixon, B. Applicability of neuro-fuzzy techniques in predicting ground-water vulnerability: A GIS-based sensitivity analysis. J. Hydrol. 2005, 309, 17-38. [CrossRef]

30. Kia, M.B.; Pirasteh, S.; Pradhan, B.; Mahmud, A.R.; Sulaiman, W.N.A.; Moradi, A. An artificial neural network model for flood simulation using GIS: Johor River Basin, Malaysia. Environ. Earth Sci. 2012, 67, 251-264. [CrossRef]

31. Chen, C.-S.; Chen, B.P.-T.; Chou, F.N.-F.; Yang, C.-C. Development and application of a decision group Back-Propagation Neural Network for flood forecasting. J. Hydrol. 2010, 385, 173-182. [CrossRef]

32. Rumelhart, D.E.; Mcclelland, J.L. Parallel Distributed Processing: Explorations in the Microstructure of Cognition: Volume 1. Foundations; MIT Press: Cambridge, MA, USA, 1986; 564p.

33. Tayfur, G.; Moramarco, T.; Singh, V.P. Predicting and forecasting flow discharge at sites receiving significant lateral inflow. Hydrol. Process. 2007, 21, 1848-1859. [CrossRef]

34. Wardah, T.; Abu Bakar, S.H.; Bardossy, A.; Maznorizan, M. Use of geostationary meteorological satellite images in convective rain estimation for flash-flood forecasting. J. Hydrol. 2008, 356, 283-298. [CrossRef]

35. Jiao, L.C.; Wang, L. A novel genetic algorithm based on immunity. IEEE T. Syst. Man. Cy. A 2000, 30, 552-561. [CrossRef]

36. Li, H.H.; Li, M. A New Method of Image Compression Based on Quantum Neural Network. In Proceedings of the 2010 International Conference of Information Science and Management Engineering, Xi'an, China, 7-8 August 2010; pp. 567-570.

37. Yan, T. An Improved Genetic Algorithm and Its Blending Application with Neural Network. In Proceedings of the 2010 2nd International Workshop on Intelligent Systems and Applications, Wuhan, China, 22-23 May 2010; pp. 1-4.

38. Ouma, Y.O.; Tateishi, R. Urban Flood Vulnerability and Risk Mapping Using Integrated Multi-Parametric AHP and GIS: Methodological Overview and Case Study Assessment. Water 2014, 6, 1515-1545. [CrossRef]

39. DHA, U. Internationally Agreed Glossary of Basic Terms Related to Disaster Management; UN DHA: Geneva, Switzerland, 1992.

40. Crichton, D.; Mounsey, C. How the Insurance Industry Will Use Its Flood Research. In Proceedings of the Third MAFF Conference of Coastal and River Engineers, Newcastle, UK, 3-5 July 1996; pp. 131-134.

41. Jenks, G.F.; Caspall, F.C. Error on Choroplethic Maps-Definition, Measurement, Reduction. Ann. Assoc. Am. Geogr. 1971, 61, 217-244. [CrossRef]

42. Wu, Y.N.; Zhong, P.A.; Xu, B.; Zhu, F.L.; Ma, B. Changing of flood risk due to climate and development in Huaihe River basin, China. Stoch. Env. Res. Risk A 2017, 31, 935-948. [CrossRef]

43. Dawod, G.M.; Mirza, M.N.; Al-Ghamdi, K.A. GIS-based estimation of flood hazard impacts on road network in Makkah city, Saudi Arabia. Environ. Earth Sci. 2012, 67, 2205-2215. [CrossRef]

44. Jongman, B.; Kreibich, H.; Apel, H.; Barredo, J.I.; Bates, P.D.; Feyen, L.; Gericke, A.; Neal, J.; Aerts, J.C.J.H.; Ward, P.J. Comparative flood damage model assessment: Towards a European approach. Nat. Hazard Earth Syst. 2012, 12, 3733-3752. [CrossRef]

(C) 2019 by the authors. Licensee MDPI, Basel, Switzerland. This article is an open access article distributed under the terms and conditions of the Creative Commons Attribution (CC BY) license (http://creativecommons.org/licenses/by/4.0/). 